Forthcoming in the European Journal of Philosophy

\title{
Heidegger and the Supposition of a Single, Objective World
}

\author{
Denis McManus
}

\begin{abstract}
$\underline{\text { Abstract }}$
Christina Lafont has argued that the early Heidegger's reflections on truth and understanding are incompatible with 'the supposition of a single objective world'. This paper presents her argument, reviews some responses that the existing Heidegger literature suggests (focussing in particular on work by John Haugeland), and offers what I argue is a superior response. Building on a deeper exploration of just what the above 'supposition' demands (an exploration informed by the work of Bernard Williams and Adrian Moore), I argue that a crucial assumption that Lafont and Haugeland both accept must be rejected, namely, that different 'understandings of Being' can be viewed as offering 'rival perspectives' on a common subject-matter. I develop this case by drawing on an alternative account of what a Heideggerian 'understanding of Being' might be like.
\end{abstract}

Christina Lafont has posed a fascinating challenge to those who would see something insightful in the early Heidegger's reflections on truth and understanding, a challenge which, I believe, has yet to be met. She argues that Heidegger's claims about the need for 'disclosures' of 'being', which 'found' propositions and the possibility of propositional truth, undermine 'the idealization of a single, objective world': 'the supposition of a single objective world of entities independent of language' (2000: 230, 3) and 'of any particular way of conceiving it' (1999: xv).

Sec. 1 of the paper presents the case that Lafont makes. Sec. 2 explores some responses that the existing literature on Heidegger suggest, focusing in particular on work by John Haugeland. I argue that the response that this work suggests fails because it cannot make sense of different 'understandings of Being' offering better or 
worse appreciations of a common body of objects. But that very fact points us to a better response to Lafont. Despite its importance for her argument, Lafont actually leaves largely undiscussed the key 'supposition' identified above and Sec. 3 turns to what is perhaps the most influential account of that 'supposition', that offered by Bernard Williams in his discussion of 'the absolute conception'. That discussion lends further credence to Lafont's worries but also helps further clarify the alternative response to Lafont that I will defend. It does so by drawing our attention to an assumption that Lafont and Haugeland share, one which I will argue we should reject, and by focussing our attention on a sense in which Heideggerian 'disclosures of being' ought to be understood as offering perspectives on the world and a sense in which they ought not. In the rest of the paper, I explain these different senses by drawing on an alternative account of what a Heideggerian 'understanding of Being' might be like.

\section{Lafont's criticism of Heidegger}

Lafont declares that 'the fact from which Being and Time starts, and which lies at the basis of Heidegger's philosophy as a whole.' (Lafont 2000: xiii) is that '[w]e always move about in an understanding of Being' (Heidegger 1962: 25). Only on the basis of such an 'understanding of Being' or 'disclosure of Being'1 is a world of entities and states of affairs revealed to us such that they might become the subject matter of propositions we might entertain. ${ }^{2}$ Where Heidegger goes astray, Lafont argues, is in believing that an 'understanding of Being', by virtue of being a precondition of such 'world-disclosure', is therefore 'necessarily immunized against intraworldly experience' (Lafont 2000: 229):

Such an understanding of being or world-disclosure has ... a quasitranscendental status. ... [I] it is valid a priori, ... in the sense that it cannot be

\footnotetext{
${ }^{1}$ I will use these expressions interchangeably.

${ }^{2}$ Cf., e.g., Heidegger 1962: sec. 13, 33 and 44.
} 
called into question from within, that is, by those who share it. There is no way to step outside of our understanding of being in order to check its validity, to test whether or not our understanding of being coincides with the being of the things themselves ... (Lafont 2000: xiv) ${ }^{3}$

What distinguishes Heidegger's outlook from a Kantian one is that he 'detranscendentalizes' this understanding into a multiplicity of different understandings which are also 'subject to historical change' $(2000: 111 \mathrm{n} .2,110)$. This understanding

is not the (eternal) endowment of a transcendental ego ... Rather it is merely contingent; it changes historically ... (Lafont 2000: xiv)

Lafont claims, however, that this vision of a multiplicity of 'detranscendentalised' but unrevisable 'understandings of Being' is fundamentally confused. We can identify three distinct, though related, charges.

Firstly, these forms of understanding may be 'synchronically absolute' or 'dominant' for those who share them, but a reflective awareness of their 'detranscendentalized status' must lead us to see them 'as tentative and revisable on the basis of experience' (2000: 258, 111 n. 2). '[N]othing essentially factical should have absolute authority over us' (2002: 231), so we cannot make sense of the 'contingent absolute[s]' that such understandings supposedly represent (1999: 32). Heidegger's failure to see this is his failure to 'draw all the consequences that follow from his own detranscendentalization' (2000: 111 n. 2).

Secondly, this vision undermines the notion of 'universally valid' truth: each truth will be 'relative to' an 'understanding of being', distinct domains of entities and distinct bodies of truths being revealed to distinct understandings (2000: $\mathrm{xv}) .^{4}$ 'There is no absolute truth across incommensurable understandings of being or world-

\footnotetext{
${ }^{3}$ Cf. also Lafont 1999: 61, 65, 67, and 109.

${ }^{4}$ Cf. Okrent 2002: 196: 'Dasein that live in the light of different understandings of being encounter different ranges of entities'.
} 
disclosures' (2002: 188) and Lafont concludes that such understandings are therefore 'utterly secluded and unalterable': they are each 'a coherent whole shut away in itself' and, as such, are 'incorrigible' (2000: 158, 252). ${ }^{5}$ Heidegger does indeed declare that "we cannot ask at all about the "correctness"' of a projection' of Being (1999: 229, quoted in Lafont 2000: 143) and that might indeed suggest that, for example, the historical succession of one such 'projection' by another cannot be regarded as an 'improvement in our conceptions of the same objective world' (Lafont 2000: 230). It is in this way that the 'supposition' that these different understandings and their different truths concern 'a single, objective world' would appear to be lost.

Thirdly, the process by which 'understandings of being' come to replace one another becomes a mystery. We cannot now 'conceive the historical changes in our understanding of being as a learning process' and the impression that we can must, for Heidegger, be 'just an illusion' (Lafont 2000: xv). No option remains for Heidegger, Lafont argues, other than seeing new disclosures as emerging out of the unfathomable workings of - in a nice turn of phrase - 'a demiurgic language, alien to any intraworldly activity' (Lafont 1999: 74).

\section{Possible Responses to Lafont}

How might one respond to Lafont's claims? One might take what Moore calls the 'nihilist' option (1997: 106), that of simply dispensing with the 'supposition'. Some followers of Heidegger's perhaps might be seen as embracing this option, ${ }^{6}$ and sense might perhaps be made of it. But I won't attempt to do so here and will instead focus on the 'anti-nihilist' strategy of arguing that Heidegger's outlook is not in tension with our key 'supposition' after all.

\footnotetext{
${ }^{5}$ Cf. also Rentsch 1989: 166: 'Being and Time's uncritical concept of truth as "disclosure" ... precludes the affirmation of all [time- and culture-] "transcendent" truth' (translation quoted in Young 1997: 93).

${ }^{6}$ This is how Moore reads Derrida in his 1997: 96-8, 107-8.
} 
Dreyfus (2002) offers such an argument. Lafont draws on ideas from Putnam, Kripke and Donnellan in claiming that only the use of directly referring expressions allows us to retain our 'supposition', making it possible for thinkers who possess different 'understandings of Being' to refer, nevertheless, to the same entities. ${ }^{7}$ Dreyfus challenges Lafont's criticisms by arguing that Heidegger can accommodate direct reference: indeed he claims that Heidegger's reflections on 'formal indication' show that he had 'discovered on his own' the linguistic phenomenon variously dubbed 'direct reference' and 'rigid designation' (2002: 192). However, I share Lafont's view that 'Heidegger's understanding of "formal indication" has nothing to

${ }^{7}$ Whether direct reference can carry this burden is a complex question I won't explore, a question made more complex by the further question - which I also won't explore - of what kind of 'account' of that 'supposition' one might reasonably insist on receiving: for example, Adrian Moore has argued that this 'supposition' is a 'primordial thought' (Moore 1987: 15) that cannot be given some 'further' or 'deeper' foundation. There are indications that Lafont shares Moore's assessment (1997: ch. 6) that it would take something like a brand of transcendental idealism to justify the 'supposition': she distinguishes Heidegger's 'understanding of Being' from 'a unique synthesis of apperception, valid for all rational beings', 'the (eternal) endowment of a transcendental ego (which would guarantee the objectivity of experience, and thereby the possibility of valid knowledge for all human beings)' (2002: 187, 186, italics added). (Cf. also her 2000: 61 n. 57 and 1999: 65-66). But I suspect that she also shares Moore's belief that that project is doomed and believes that the virtue of the 'direct reference' approach, which - if anything - presupposes rather than justifies the 'supposition', is merely that it is consistent with the 'supposition', whereas Heidegger's outlook is not. 
do with "rigid designation"' (2002: 233); ${ }^{8}$ and I will instead focus here on the more plausible brand of 'anti-nihilism' that can be found in the increasingly influential work of John Haugeland. ${ }^{9}$

Haugeland suggests that a certain structure in our engagement with the world 'giv[es] content to the idea of being wrong', and hence to that of 'being correct' (2002: 167). He illustrates this structure by pointing to aspects of scientific investigation and points to two forms of self-criticism that he believes are essential to 'being a genuine or honest scientist' (p. 167). The first is embodied in a concern with 'communal norms of proper performance' that govern, for example, the making of observations; such a concern 'weeds out experimental results that are compromised by sloppy or improper procedures' (p. 165). The second turns its attention to those norms themselves and arises out of the fact that 'scientific laws and principles ... sharply constrain how the results of various different experimental procedures would have to be related' (p. 166). ${ }^{10}$ This explains, among other things, why 'replication ... matters':

Inasmuch as the norms of proper performance, together with the laws governing the objects under investigation, effectively promise that the results

\footnotetext{
${ }^{8}$ Though Heidegger's thinking tells us very little about those aspects of language that theories of direct reference reveal - a charge which can, of course, be levelled at virtually every thinker prior to 1970 - it is not clear to me that Heidegger cannot accommodate some form of externalism (e.g., the view set out by Morris $2007 \mathrm{sec}$. 5.4). I also believe that it is less than clear that the argument for the fundamentality of externalist aspects of language has been won. (Cf. n. 40 below and, for some recent defences of internalism, Wikforss 2001 and Farkas 2008.) For other assessments of 'Heidegger's externalism', cf. Wrathall 2002, Carman 2002 and 2003, Lafont 2002 and 2005. I offer my own take on Heidegger's notion of 'formal indication' in my forthcoming-c.

${ }^{9}$ Cf., e.g., Smith 2007's recent use of Haugeland's ideas.

${ }^{10} \mathrm{Cf}$. also Haugeland 2000: 60-61, 71-72 and 2007: 101-2. Other relevant discussions include chs. 10 and 13 of his 1998.
} 
will agree, any disagreement means there's something wrong somewhere. Of course, the most common upshot is that, on closer examination, one or the other of the experiments was not properly performed after all. Most apparently conflicting results are actually due to experimental error.

But the more interesting case is when no such error can be found. Then scientists turn their scrutiny not on individual performances but on the very norms that determine procedural propriety for all performances of that sort. (Haugeland 2002: 166)

According to Haugeland, Heidegger shares precisely this vision and sees the second form of self-criticism as the means by which 'understandings of Being' might too be attacked or legitimated. Haugeland's Heidegger believes that 'intransigent discovered impossibilities undermine a disclosure of being' and that, by virtue of that fact, such a disclosure is "beholden for its "success" to discovered entities (2000: 73, 76). Once 'careful and persistent double-checking has eliminated the discoveries as the culprit'that is to say, once we have discounted 'sloppy or improper' application of the observational procedures in which, as we will see below, an understanding of Being is embodied - that 'leaves the possibilities - in other words, the being of the entities discovered' (Haugeland 2000: 72): our critical gaze falls on the 'understanding of Being' itself.

Viewed as a response to Lafont's worries, this view works, in one sense, by softening the distinction between 'understandings of Being' and particular truths that one might discover concerning particular entities. Haugeland glosses 'the Being of entities' in the following way:

The being of entities is that in terms of which they are intelligible as entities. The qualifier 'as entities' (as I am using it) is short for this: with respect to the fact that they are (at all) and with regard to what they are. (Haugeland 2000: 47) 
He presents as an example of this the way in which physical entities are 'intelligible via physical theory, especially the basic laws that specify how they can and must relate to one another' (2000: 48$)$ :

[T]he laws governing the objects are crucial to the very intelligibility of those objects as what they are. [For example,] how could one possibly understand what mass, force, momentum, and energy - not to mention electrons, orbiting planets, springs, and gasses - are, apart from how they figure (in relation to one another) in the relevant laws of motion, gravity, elasticity, thermodynamics, and so on? (Haugeland 2002: 171)

But while Haugeland softens the distinction between 'understandings of Being' and particular truths that one might discover concerning particular entities, he does not collapse it, because the undermining of the former has a special significance by virtue of the fact that the "the means of discovering entities ... themselves depend on the disclosure of the being of those entities':

The design of scientific instruments and experiments and the interpretation of their results depend essentially on the very laws and theories they sometimes test. Without a great deal of accepted physics, for instance, no cloud-chamber image or statistical pattern from a cyclotron could so much as make sense, let alone reveal anything. (Haugeland 2000: 73)

In principle, therefore, the results of such testing can have radical consequences: they can undermine the very 'disclosure of Being' in terms of which they are understood and thereby 'pull[] the rug from under themselves ... along with ... any other discoveries and abilities to discover in that region' (p. 73). Unlike mere 'factual mistakes', which can be 'identified and corrected' and 'life goes on' (p. 75), the collapse of a 'disclosure of Being' is the collapse of a whole perspective on things. Indeed Haugeland sees here a basis on which we might understand Heidegger's invocation of the notion of death: the collapse of a 'disclosure of Being' 'is a 
systematic breakdown that undermines everything'; as a whole way of seeing and investigating the world collapses, "that life ... does not "go on"”: '[t]his is why Heidegger speaks of death' (pp. 75, 73).

How adequate a response, then, does Haugeland's account offer to Lafont's challenge? She shares Haugeland's sense of the kind of view Heidegger ought to be presenting; but Lafont makes a strong textual case for thinking that he doesn't do so: in particular, I believe that she is right to think that Heidegger denies the possibility of 'understandings of Being' being 'revisable on the basis of experience' (2000: $111 \mathrm{n}$. 2), the discovery of 'intransigent impossibilities' included. I won't consider that case here. Instead I will present another reason to doubt whether Haugeland's account can answer Lafont's criticisms, reasons that remarks of Dreyfus' suggest.

Although Haugeland's Heidegger sees 'understandings of Being' as 'corrigible', it is unclear how Haugeland's story can allow us to see a succession of 'understandings of Being' as an 'improvement in our conceptions of the same objective world' (Lafont, quoted above). If abandoning an 'understanding of being' 'is a systematic breakdown that undermines everything', then it's unclear how one moves on to a superior 'understanding of being' from there. As Dreyfus asks, does 'something remain[] aware of the collapse and survive[] to open a new world' (2005: $x x x v)$ ? If all that remains is 'a pure, isolated, world-needy mineness' ( $p . x x x v$ n. 59), it's not clear that the 'stage-setting' - to use a Wittgensteinian turn of phrase ${ }^{11}$ - is in place that would allow us to arrive through a 'learning process' at a grasp of 'the new world' and for that grasp to be an improvement on our grasp of 'the old'.

${ }^{11}$ Cf. Wittgenstein 1967: sec. 257. In defending my reading of Heidegger, I will draw on Wittgensteinian ideas at a number of points below and this use may also suggest ways in which one might defend Wittgenstein himself from claims made against him that are analogous to those that Lafont makes against Heidegger: I have in mind Williams (1974)'s influentially ascription of linguistic idealism to Wittgenstein and Nagel's claim that Wittgenstein 'cut[s] the world down to size' by making it 'dependent on our view of it' (1986: 108-9). I won't attempt to make good on this suggestion here but McManus 2003 explores some of the notions discussed here specifically in connection with Wittgenstein. 
One might worry that this objection rests on too literal a construal of Haugeland's talk here of 'death'. ${ }^{12}$ But what is, in essence, the same objection arises even before one draws on that rather radical extension of Haugeland's reading: to be specific, an independently intelligible body of observations that might perplex one 'understanding of Being' and be better accommodated by a another, new 'understanding' would seem to be missing. It is unclear that we can envisage, as Dreyfus does in an earlier discussion of Haugeland's work, our 'disclosing a new world in which these anomalies make sense' (Dreyfus 2000: 315), as a difficult question here is: which anomalies? If discoveries, like the "the means of discovering entities', 'themselves depend on the disclosure of the being of those entities', then it is unclear how these same discovered entities might be identified by another 'disclosure of being' which we might conceive of as making better sense of them, rendering them no longer 'anomalous'. Haugeland's account may make sense of the notion of discovered entities undermining a 'disclosure of being' but it's not clear how such entities might then be seen as better accommodated by another 'disclosure'; there would seem not to be a common stock of discoverable entities to which a variety of different, rival 'disclosures' might be 'beholden for [their] "success"'. 13

A full analysis of Haugeland's rich and thought-provoking account and of the resources it might yet prove to have at its disposal in addressing this kind of charge is

\footnotetext{
${ }^{12}$ Heidegger distinguishes 'death' from 'perishing' and 'demise' (1962: 284 and 291) and Haugeland's account incorporates that. How, and how successfully, are questions I won't consider here.

${ }^{13}$ For a related worry, cf. Beck's proposal that, when we are forced to 'relinquish [an] understanding of Being', 'it is not at all clear that Haugeland can say anything about what happens next' (2005: 168, 175-76). My reading offers an explanation of that awkward silence.
} 
beyond what I can offer here. ${ }^{14}$ What I will offer instead is an alternative defence of Heidegger from Lafont's charges, one which takes as its critical focus precisely the thought that I have suggested Haugeland struggles to accommodate, namely, that of there being a common set of discovered entities revealed to more than a single 'understanding of being'. 15

But first I want to examine another presentation of our key 'supposition', that found in Bernard Williams' reflections on the 'absolute conception'. Despite its importance for her argument, Lafont says very little about the 'supposition', seemingly seeing it as a straight-forward intuition. But if, with Williams, we examine more thoroughly just what the demands of that 'supposition' are, we will see a Lafontian case for the corrigibility of Heideggerian 'disclosures' emerge but in a way that makes clear that that case rests on a key presupposition. It is a questionable presupposition which Lafont and Haugeland share, namely, that such 'disclosures' embody rival perspectives on what there is.

${ }^{14}$ One particular issue that such an analysis would need to address is how exactly one ought to understand the analogy that Haugeland suggests between 'understandings of Being' and natural scientific laws. What further complicates that issue is Haugeland's rather unorthodox views of the nature of laws (cf., e.g., sec. 3 and 5 of his unpublished).

15 The literature does, of course, include, and in other ways suggest, other ways in which Lafont might be challenged. For example, Carman 2002, Okrent 2002 and Wrathall 2002 have argued that Lafont is mistaken in depicting the early Heidegger's 'disclosures of being' as essentially linguistic in character. But I think that Lafont is right to claim that this particular criticism misses the mark: 'My concern here is the allegedly a priori status of such an understanding and not its specific structure or content. If it turned out that our cognitive capacities are essentially determined by our prelinguistic interpretive access to the world, I would not feel any better about it' (Lafont 2002: 244). Despite his other criticisms of Lafont, Carman shares with her what would seem the crucial worry: that 'Heidegger remained committed to a kind of ontological apriorism' (2002: 206, cf. also p. 214). One of the reasons why I have focused on Haugeland's work is that it questions precisely that commitment. 


\section{Williams and 'Knowledge of What is There Anyway'}

In his Descartes: The Project of Pure Enquiry, Williams sets out a 'very basic thought' about knowledge:

If knowledge is what it claims to be, then it is knowledge of a reality which exists independently of that knowledge, and indeed (except for the special case where the reality known happens itself to be some psychological item) independently of any thought or experience. Knowledge is of what is there anyway. (Williams 1978: 64)

Unlike Lafont, Williams believes that this thought - though 'very basic' - has 'consequences [that] can seem both demanding and puzzling', so puzzling in fact that this thought articulates 'something in [knowledge] which offers a standing invitation to scepticism' (p. 64). But we will only follow Williams part of the way down that road; here is where it begins:

Suppose $A$ and $B$ each claim to have some knowledge of the world. ... [W]ith respect to their supposed pieces of knowledge, $A$ 's and $B$ 's representations may well differ. [But i]f what they both have is knowledge, then it seems to follow that there must be some coherent way of understanding why these representations differ, and how they are related to one another. One very primitive example of this would be that $A$ and $B$ were in different places ... In [such a] case, a story can be told which explains how $A$ 's and $B$ 's can each be perspectives on the same reality. To understand this story, one needs to form a conception of the world which contains $A$ and $B$ and their representations; $A$ and $B$ are not debarred from taking this standpoint themselves, but it involves their standing back from their original ways of representing these aspects of the world. (Williams 1978: 64-65) 
'This process, it seems, can be continued', Williams observes, leading ultimately to what he has famously labelled 'the absolute conception'. Williams argues that, since that 'conception' appears to be 'basic to the notion of knowledge itself' (1978: 65) and yet there appear to be reasons for doubting whether we can give content to that 'conception', ${ }^{16}$ a form of scepticism looms. But I won't concern myself here with that scepticism or with those apparent reasons. I will only consider the less obviously 'puzzling' - indeed seemingly 'incontestible' - 'need' (1978: 64) set out at the end of the quoted passage.

The passage presents a certain kind of explanation, embodied in the 'containment' of 'local' representations within further, encompassing, less 'local' representations, a containment that explains how and why the world comes to seem the way that it does by virtue of people occupying different points of view. Explaining 'how the more local representations of the world come about' 'would enable us to relate them to each other, and to the world as it is independently of them' (Williams 1978: 245-46), as it is anyway. For example,

[W] hen we understand, or merely have some vague idea of, the kinds of processes that underlie the phenomena of colour... we can easily understand why a thing should seem one colour to one person, another to another; or, again, why it should seem coloured to members of one species, monochrome to members of another. (Williams 1978: 241)

The account that underpins such explanations of 'the existence of rival views' will, in some of those cases, serve as 'a theory of error' (1978: 301), explaining, for example, why certain members of a species at certain times will make judgments that they and others of their species would reject under what that theory suggests are better conditions for the making of such judgments. In such a case, the theory suggests that a 'supposed piece of knowledge' turns out not to be knowledge after all. This kind of criticism would also appear to be applicable on a more general level, leading us, for

${ }^{16}$ Cf. Williams 1978: 65 and 300-303. 
example, to ascribe to members of a particular species a superior capacity to judge particular matters of fact than is possessed by members of another species. A space seems to open up here for reflection on how representations 'work', on how they 'relate ... to the world as it is independently of them', such that some can be called accurate and others not and the perspectives from which different individuals or species judge accurate or not.

We are now in a position to see how these reflections might seem to pose a problem for Heidegger and substantiate Lafont's critical invocation of our crucial 'supposition'. Long before one attempts to reach the (perhaps unreachable) 'absolute conception', our conceiving of different 'understandings of Being' as directed at a single, unified world would seem to require the possibility of our 'standing back from' those understandings and placing them within a more encompassing, less 'local' perspective. That perspective would explain how the representations of the world that these understandings 'found' 'come about'; it does so by 'relat[ing] them to each other, and to the world as it is independently of them' (Williams, quoted above). But the possibility of such a perspective would give sense to a question of accuracy about 'understandings of Being' and open up a space for their criticism: the more encompassing picture presents such understandings as either 'working' or not 'working', and if the latter, then as a fit object for 'a theory of error'. If one instead wishes to maintain the 'incorrigibility' of such an understanding, one would seem to need to reject this possibility and, in doing so, seem to reject our key 'supposition'.

But Williams' account also suggests a rather different response. In the context in which it was initially presented, that account was as much a story of how apparent conflict can turn out not to be real conflict, of how apparently competing claims may turn out to be compatible, true of the same unified world. Examples of kinds of case that Williams has in mind are that 'It's raining' and 'It's not raining' can both be true and 'It's raining' both true and false - if these sentences are uttered in different locations: if that condition holds, the claims made simply address different bodies of 
fact. ${ }^{17}$ So what Williams' account of our key 'supposition' brings out much more clearly than Lafont's - in as much as she provides one - is that two claims provide reason to think one must be subject to an 'error theory' only if the fact that they compete with one another has been secured. According to the account of 'understandings of Being' I will offer, such 'understandings' do not compete. Like 'It's raining' and 'It's not raining' uttered in different locations, they address different bodies of fact. But there is also a respect in which comparing such 'understandings' to such 'perspectival claims' is deeply misleading, as I will explain.

The possibility of criticism described above only arises if 'understandings of Being' are understood as perspectival in the sense that they offer different 'takes' on some common target, 'takes' whose power to illuminate or obscure might then be understood and assessed by our 'standing back from' them and adopting a further, less 'local' 'take' on them and that target. We see the same presupposition in Lafont's argument: 'understandings of Being' must be corrigible, as otherwise we cannot see them as better or worse 'takes' on what there is, and such 'understandings' can only be incorrigible if 'secluded', that is, if there is 'no absolute truth across ... understandings' (Lafont, quoted above, italics added). Here too, the claim that 'understandings of Being' must be capable of correcting another rests on the assumption that they compete with one another. The same assumption is also at work in the response to Lafont that Haugeland's work suggests, though, as I argued above, that response cannot ultimately make sense of that assumption. That response needs to identify common 'discovered entities' by reference to which one 'understanding' might be judged superior to another; and it founders, I suggested, because it fails to do

\footnotetext{
${ }^{17}$ In Moore's terms, the former utterances may be of opposed types but not express incompatible contents, and the latter may be of the same type but express different contents (1997: 9-11).
} 
so: it can't make sense of 'comparing' 'understandings' sharing a common 'target'. ${ }^{18}$ But that this is what we need to make sense of if we are to defend Heidegger from the kind of charge Lafont makes is itself taken for granted. I will argue that a different defence opens up precisely here where Haugeland's comes to grief, in the possibility that there may not be common targets 'across' different 'understandings of Being'.

\section{4, On the World, its Aspects and Common 'Targets'}

To take two of the very few examples of 'disclosures of Being' that the early Heidegger's work offers, our understanding of the world as Zuhanden and our understanding of the world as Vorhanden reveal what one might call different 'aspects' of the world and they do so in such a way that they do not compete with one another; they reveal different bodies of fact, not the same body of facts more or less well. In this sense, it is clear that being about the same world does not require mutual corrigibility; only being about the same aspect of the world - the same body of facts does that. So what if different 'understandings of Being' stand to one another not - as Haugeland's analogy might suggest - as different theoretical accounts of the physical stand to one another, but instead - to extend our proposal a little further - as claims about objects' colours stand to claims about their owners, or their ages, or their distance from the Eiffel Tower?

Someone persuaded by Lafont's case might respond to this simple proposal in a number of ways. One response, which I will consider only briefly here, runs roughly as follows. 'For there to be a single unified, objective world, there cannot be a multiplicity of "aspects" of the sort to which you have referred. All true descriptions

\footnotetext{
${ }^{18}$ Haugeland's account derives its apparent plausibility, I suspect, partly by exploiting our unexamined sense that we already have a clear grasp of what we mean by 'physical entities', such that these provide an independent and clearly shared 'target' for different specifications of 'physical theory', different sets of 'basic laws that specify how [such entities] can and must relate to one another'. The objection I raised to that account questions whether Haugeland is entitled to trade on such a sense.
} 
of the world must ultimately turn out to be of a single "aspect", otherwise we will have a multiplicity of "secluded" truths about the world and no absolute and universally valid truth, as befits a single, objective world.' A natural candidate for this single aspect might be 'the physical', the claim then being that all true descriptions must ultimately turn out to be descriptions of physical features of the world.

There is indeed a sense in which Williams' reflections point us in this direction; ${ }^{19}$ but one also finds in his work a recognition of problems that one comes to confront in following in that direction. Among these are well-known problems for physicalism, problems that lead Moore to characterise the most that the 'absolute conception' can hope for as the 'indirect integration' of the many truths of our single, objective world, where a representation that 'indirectly integrates' others is one that 'weakly entails' them $(1997: 22,16)$. To those considerations one might add those found in Haugeland's discussion of 'global supervenience' (in chs. 5-6 of his 1998), Fodor 1974's and Dupre 1983's discussions of the 'disunity of science', and wellknown functionalist reflections. I cannot hope to discuss these reflections in any depth here or to settle here whether they embody insoluble problems for reductive physicalism. ${ }^{20}$ But I do want to draw attention to the fact that, if it is to be defended in

${ }^{19}$ Cf. Moore 1997: 28-30 and 75-76.

${ }^{20}$ For what it's worth, I believe that there is room for relations of supervenience between what different Heideggerian 'understandings of Being' reveal, given that there are reasons to believe that such relations cannot be required to be overly 'strong'. A kind of functionalism might represent a way of understanding the relation between Heidegger's Zuhandenheit and Vorhandenheit, for example, according to which these different 'understandings of Being' are both about a single world but are also clearly compatible. (For discussion of some of these issues, cf. McManus 1999.) I also believe that my view leaves room for theories which predict what the outcome of a particular exercise of a practice of measurement of the sort I will go on to consider - if carried out correctly - should be on a particular occasion. What I believe we are confused to expect is an explanation that would (somehow) show that the 'norms of proper performance' of these practices themselves count as 'correct', the vindication of what counts as vindication referred to in Sec. 7 below. 
the manner that the previous paragraph outlines, Lafont's critique now rests on premises that are much more contentious than her own presentation of her argument suggests.

Another potential Lafontian response runs as follows. 'The different "understandings of Being" that you have alluded to may reveal different aspects of reality - and, for that reason, do not conflict with one another - but we can still imagine different "understandings" of any one such aspect arising; these would be incompatible - would compete - and that opens up the possibility of corrigibility once again.' I will argue that, with the right examples before our minds, this claim can be seen to be false. Seeing that requires that we recognize the potentially misleading aspect of the analogy between perspectives and 'understandings of Being' that I invoked above. We must distinguish two senses in which something might be said to be 'a perspective': it may take in one particular aspect of the world, or it may take in some particular object which might also be taken in by another such 'perspective'. ${ }^{21} \mathrm{I}$ will argue that 'understandings of Being' are perspectives only in the first sense.

In the remainder of this paper, I will offer a way of thinking about Heideggerian 'understandings of Being' which differs from that which Lafont and Haugeland's discussions suggest. Building on an earlier presentation of mine, I will question the assimilation of such 'understandings' to 'takes' on the world, whose 'accuracy' might then be subject to the kinds of confirmation or disconfirmation that Williams' and Haugeland's accounts envisage. In the cases I will consider, and which, I suggest, offer our best models for 'understandings of being', belief in the possibility of reflectively 'standing back from' and 'revising' such 'understandings' is much less compelling, because the possibility of there being rival 'understandings' - 'rival views' - is much less compelling. By the same token, however, the notion that such a 'disclosure' offers no more than $a$ 'tentative and revisable' take on the world is also deprived of content: pace Lafont, we are not entitled, one might say, to the suspicion that these 'original ways' present anything less than 'what is there anyway'.

\footnotetext{
21 These different senses would seem to correspond to Moore's 'points of view' and 'outlooks' (1997: 81).
} 


\section{Practices of Measurement}

Heidegger clearly believes that the mode of understanding proper to the readyto-hand [Zuhanden] provides us with what is, in some sense or other, a better model of understanding in general. The account I have offered elsewhere focuses upon the fact that the forms of intelligent action that Zuhanden objects involve, and which demonstrate our understanding of those objects, are themselves characterised by reference to the 'objects' that they involve and - crucially - therefore cannot be seen as fitting those 'objects'. I will give a brief indication here of the account that emerges.

Hammering, for example, is an activity that involves hammers: it is an activity that takes place among - as Heidegger would say, 'bei' (1962: 80) - particular objects, a way of using particular objects that cannot be characterised except by reference to those objects. One can, of course, distinguish the craftsman from his tools; but what makes him a craftsman is something to do with those tools: to understand what he does (hammering, say) is to understand the objects with which he does it (hammers) and to understand those objects is to understand what it is that he does. Heidegger tells us that such an object 'can genuinely show itself only in dealings cut to its own measure (hammering with a hammer, for example)', and hammering 'appropriates' hammers 'in a way which could not possibly be more suitable' (Heidegger 1962: 98, italics added). This is so, I suggest, because here the activities of the subject - the person - are not constituted independently of the relevant objects. ${ }^{22}$ For this reason, it also makes no sense to talk of the former as corresponding to - or fitting - the latter.

On the basis of suggestions of Heidegger's such as that 'theoretical research is not without a praxis of its own' (Heidegger 1962: 409) and his repeated invocation of the motif of measurement in articulating his sense that propositional knowledge is 'founded',23 my account goes on to argue that the above feature also marks our grasp

\footnotetext{
${ }^{22}$ A similar thought can be found in Olafson 1987 p. 107 and Blattner 1999 p. 58:

'Dasein's abilities-to-be are interdefined with the functional roles served by paraphernalia.'

${ }^{23}$ For documentation, cf. McManus forthcoming-a: sec. 5.4.4.
} 
of some basic physical characteristics of the world around us: in other words, the bearing of the above remarks extends beyond what one might think of as the province of the Zuhanden and into that of what is typically classed as the Vorhanden. At least in certain basic cases, the 'practical' achievement of mastering measurement procedures and the use of measurement tools is not merely learning a means for describing or accessing certain kinds of characteristic; rather it is learning what kinds of characteristic these are. For example, someone who did not understand that to measure the length of an object one needs to lay the measuring rod straight along it, as opposed to criss-crossing along it, is best described as being ignorant - not about, but - of lengths. Laying the measuring rod straight along the object is not, so to speak, the best way of measuring lengths; rather that is what it is to measure lengths. Here too the activities of the subject - laying the measuring rod straight along the object - are not constituted independently of those of the relevant objects - the characteristic being measured being their length. For this reason, we cannot make sense here of 'alternative' or 'rival practices' which have the same object as - but also understand that object differently from - what we might be tempted to call 'our own practice'. We cannot see our 'own practice' as 'fitting' - 'corresponding' to - those objects, while other, 'alternative practices' might be thought to fail to do so. Crucially for our present purposes, we cannot make a case for 'our own practice' - or to echo Williams, our 'original ways of representing these aspects of the world' - being merely one 'take' on those aspects or give sense to the notion that we are 'confined' to only that particular understanding of those aspects, to what we might confusedly conceive of as 'our understanding' of them. These realisations provide a sense for the claim that "we cannot ask at all about the "correctness"" of a projection' of Being (Heidegger, quoted above), a sense that does not entail a problematic idealism and that has application in connection with what we might think of as central cases of our grasp of objective features of reality.

\section{On the Absence of 'Rivals'}


The kind of criticism of a perspective or descriptive practice that Haugeland and Williams envisage is surely legitimate when applied to descriptive techniques of a certain complexity, such as that embodied in the use of instruments of the complexity of a cloud chamber or an electron microscope. It might also be argued that they apply to some techniques that have become utterly familiar to us and of whose initial justification we need history of science to remind us. ${ }^{24}$ But does that possible criticism have an intelligible bearing on the yet more basic kinds of descriptive practices that I have described? In the construction and use of instruments such as cloud chambers, we have a clear sense of something akin to a means-ends distinction: a distinction between what one is trying to measure and how one is trying to measure it. But it is not clear that the same distinction can be projected in an illuminating way on to the practices with which I have concerned myself. ${ }^{25}$

The following remarks of Wittgenstein's echo my earlier claim that we engage in our practice of measuring length not because this is the best way to measure length but because this is what it is to measure length:

One judges the length of a rod and can look for and find some method of judging it more exactly or more reliably. So - you say - what is judged here is independent of the method of judging it. What length is cannot be defined by the method of determining length. - To think like this is to make a mistake. What mistake? - To say 'The height of Mont Blanc depends on how one climbs it' would be queer. And one wants to compare 'ever more accurate measurement of length' with the nearer and nearer approach to an object. But in certain cases it is and in certain cases it is not, clear what 'approaching

${ }^{24}$ Cf. e.g., Haugeland's discussion of Galileo's need 'to show, step by step, question by question, that what appeared in the telescope really was something "out there"" (2007: 99).

${ }^{25}$ Sec. 8 considers another example. Drawing a neat line between these two kinds of case may also not be possible. Instead it may be that we must explore in each case whether we really have given sense to the 'logical space' within which a means-ends distinction might open up. 
nearer to the length of an object' means. What 'determining the length' means is not learned by learning what length and determining are; the meaning of the word 'length' is learnt by learning, among other things, what it is to determine length. (Wittgenstein 1967: 224-25)

The conceptual room necessary to imagine these particular practices as accurately acknowledging what is there, while others - rivals - do so inaccurately, seems then to be missing: these modes of 'determination' are among those cases about which we cannot tell a story of a 'nearer and nearer approach' ${ }^{26}$ It may, of course, appear that we can, but appearances can be deceptive: to take just one kind of example, and to draw on a distinction that Chang and Cartwright (2008) usefully discuss, I have argued elsewhere that many of the ways in which we may see the practices I have discussed as having been 'improved upon' are best understood as improvements in precision rather than accuracy. ${ }^{27}$ To give here no more than a rough analogy, coming to be able to measure to two decimal places may be a more precise form of measurement than measuring to one decimal place, but it does not follow that the latter form of measurement is any less accurate: one might say that the former measurements answer a question that the latter measurements did not answer incorrectly but rather simply didn't address.

It is my suspicion that we have no clear sense of the possibility that the practices under discussion might be 'corrected' - that there might be 'alternative' or 'rival' practices switching to which would be a 'nearer approach to' the very objects

${ }^{26}$ I argued above that we have no clear conception of the measuring practices in question without invoking the 'objects' of that measurement, and I would suggest that we can plausibly add 'and vice versa', in that the person who masters such procedures knows what length is and the person who hasn't doesn't, irrespective of how much physical theory they may be able to parrot. This is not to deny that many questions remain: for example, would this mean that a person paralysed from birth could not come to grasp what lengths are? Cf. Collins and Evans 2007 for this worry regarding a range of views that give prominent roles to 'practical skills' in cognition.

${ }^{27}$ Cf. McManus forthcoming-a: sec. 6.3.2 and 2007. 
of our original practices - or that particular findings of theirs, which have been correctly judged to be correctly carried out by the lights of these practices, might turn out to be wrong. Haugeland's second kind of self-criticism, the kind of criticism that he sees as directed at the Being of the entities disclosed, envisages our finding fault with measurements that, by the lights of the relevant practices, have been executed correctly. It is the norms embodied in those practices that are subject to that kind of criticism; but it is not clear that we understand what it would be to subject the norms of the practices that I have been considering to criticism. One can certainly imagine other practices with other norms: the above case of a criss-crossing use of a measuring rod is an example. But it is not clear that these would count as better (or worse) attempts to measure the same thing; these would be 'means' to other 'ends', at best determining how other bodies of fact stand. ${ }^{28}$

\section{Reflection, Idealism, and Concepts of 'Perspective'}

In his discussion of Williams, Moore describes the pursuit of a point of view on 'things in general' as a 'goal of rational reflective self-understanding' and indeed as a requirement for 'full self-consciousness' (1997: 22). In moving towards this view of 'our place in the wider scheme of things', 'we begin to see why ... situations look the way they do from [particular] points of involvement', attaining 'a less narrow, less tainted, and less distorted conception of things' and, in some cases, 'vindicating' our initial views (pp. 25, 35). Such self-consciousness seems familiar and intelligible but also incompatible with the Heideggerian vision of 'understandings of Being' as incorrigible; and I have indicated what indeed might be perceived as a limit on reflection, criticism and vindication, an obstacle to 'full self-consciousness'. A certain kind of reflective self-understanding clearly does remain possible: I can give reasons why a particular measurement failed or ought not to be taken seriously, such as 'The object slipped' or 'The ruler bent', and by showing that such eventualities didn't arise,

\footnotetext{
${ }^{28}$ Ironically, this argument is similar in some respects to that which Lafont makes against what she calls 'the incommensurability thesis' (2000: 273-75).
} 
I may vindicate other such measurements. But a further form of reflection, of a form that would correspond to Haugeland's second kind of self-criticism, does seem to be absent here: we are denied vindications of these vindications and explanations which would let us see why the reasons mentioned are good reasons why such a measurement might have failed. But can we actually give content to the forms of reflection that we feel we miss here? I have suggested that it is confusion on our part that creates the impression that we can and this section will try to refine what that confusion is.

Lafont proposes that Heidegger's view of an understanding of Being as 'a totality shut off in itself' requires 'the presupposition of a lack of alternatives', but that 'in the case of the sciences, this presupposition is seldom satisfied' (2000: $286 \mathrm{n}$. 20); I agree that that view only applies plausibly where that presupposition is satisfied but have suggested that there are interesting cases where it is. Among these one finds some of the most basic forms of understanding we possess; and that surely ought not to be surprising. But whether we are entitled to talk of these modes of understanding as 'secluded', as 'totalities shut off in themselves', depends on whether we can give sense to their being exposed to criticism or to a corresponding reflective vindication; and it's not clear that here we can. If so, we should reject the insinuation of a certain failure of reflective or critical awareness and, for the same reason, reject both Lafont's ascription to Heidegger of a brand of idealism and Haugeland's corresponding claim that 'understandings of Being' are 'arbitrary' if not 'grounded' in the way he envisages (2000: 76).

Lafont does consider Heidegger's invocations of the motif of measurement but, I believe, misreads them. Lafont states that, in such passages, when Heidegger refers to 'a standard of measurement', he means a 'factual standard of measurement for the ascertainment of truth (... a criterion of truth)' (p. 127 n. 20). Thus, for her Heidegger, 'truth is identified with ... specific, historically changeable standards for ascertaining truth' (p. 168). Having ascribed to Heidegger this assimilation of a criterion of truth - a specification of how one might go about determining whether a particular proposition is true - to a definition of truth - a specification of what it is for a proposition to be true - Lafont sees Heidegger as guilty of an 'exceedingly dubious' 
'epistemologization of truth' (2000: 155, 149, cf. also 166). But in the cases that I have presented, such an assimilation is harmless precisely because we have no grasp of the states of affairs in question other than through the methods of measurement in question. $^{29}$

This view, however, might itself seem to point to a kind of idealism. To bring out how, let us return to Lafont's argument that Heidegger's 'detranscendentalization' should have led him to a 'fallibilism' about 'understandings of Being', to the realisation that "nothing essentially factical should have absolute authority over us' (2002: 231, quoted above). One could make this criticism of 'contingent absolutes' in another way. If our 'understanding of being' is 'constitutive for our access to the innerworldly' then that 'understanding' would seem to be 'insurmountable': we would be unable 'to distance ourselves from it reflexively' (Lafont 1999: 67). If so, that might seem to undermine Heidegger's 'detranscendentalization', in that the possibility that our understanding is only one among many possible understandings would seem to be one that we could not entertain. (The next section will offer a different construal of that 'detranscendentalization'.)

These reflections might still seem to point to a form of idealism, a particularly striking form but one familiar from discussion of Wittgenstein's Tractatus. According to this form of idealism, the fact that we cannot grasp these alternatives does not show that idealism to be false: the fact that we cannot think these 'alternatives' is precisely what this form of idealism would entail and makes clear the peculiarity of this idealist insight, that it is, in a sense, ungraspable, certainly ineffable. But I suggest that here we ought to remain - to use an expression from the Tractatus literature - 'resolute'. ${ }^{30}$ We are not entitled to the notion that we are 'confined' to a particular 'understanding of Being', one that we come to label 'our understanding', as would seem to be required by both idealist construals of the above claims and demands such as Haugeland's that we 'ground' those 'understandings'; we have failed to give that notion sense because we have failed to give sense to the notion of 'rival'

${ }^{29}$ Lafont seems closer to the kind of insights I emphasise at 2000: 58, 60, 69-70 and 75.

${ }^{30}$ Cf. Goldfarb 1997. 
'understandings'. It is not that our 'factical 'disclosure' - as 'a fate into which [we] are thrown' (2000: xiv) - renders us unable 'to distance ourselves reflexively' from 'our understanding' but rather that we have yet to give sense to what that 'reflexive distancing' might involve. We confront not 'something we cannot do', as Wittgenstein might have put it, ${ }^{31}$ but rather something we simply haven't done.

There is then something misleading in describing the practices we have discussed as 'ours', as 'local' or - in one sense - as 'perspectival'. To make a point that echoes both Davidsonian and Wittgensteinian thoughts, ${ }^{32}$ any agent we might interpret as intentionally related to lengths will have to display in its activities something akin to 'our' measuring practices; ${ }^{33}$ and although there is a sense in which such 'disclosures' might be understood as offering perspectives on the world, there is also a sense in which they ought not to be. They only reveal part of what there is; but

${ }^{31}$ Cf. 1967: sec. 374.

${ }^{32}$ Cf., e.g., Davidson 1973-73. We also pass close by themes from the literature surrounding the notion of a 'disappearing "we"” (e.g., Lear 1984 and Rorty 1972), to which Williams 1974 was a major contribution.

${ }^{33}$ There are, of course, more complex 'technologies' for measuring length than that which involves the use of measuring rods, such as our 'measuring atomic distances [by] putting together some complicated equations of electromagnetic theory or quantum physics with some observable quantities' and 'measuring astronomical distances ... starting with the measurement of the time light takes in reaching an object and travelling back after being reflected' (Chang and Cartwright 2008: 368). But my suspicion (and I won't attempt to make it more than that here) is that the establishment of these new and more complex 'alternatives' is still an inherently 'conservative' business, in that they establish their credentials - their claims to be methods for measuring lengths - by showing, roughly speaking, that their results are in line with the 'old' methods when applied to those phenomena to which we can apply both methods. (Cf. again Haugeland's discussion of Galileo, cited in n. 24.) Something similar ought to be said, I'd suggest, about the experienced measurer's capacity to judge lengths 'by eye', which might appear to be another 'alternative' to 'using our measuring practices'. 
there is, for instance, no element of perspective that must be purged from the representations that these 'disclosures' yield ${ }^{34}$ if we are to be able to endorse them alongside other representations true of our single, unified world. Unlike the likes of 'It's raining', these representations can be combined with others by what Moore calls 'simple addition' (1997: 14) and, if so, and if an 'absolute conception' is indeed possible, there is no reason to think that they need be excluded from it. ${ }^{35}$ This might seem to deny us some further, 'fuller' 'self-consciousness' regarding how these practices work; but that is as it should be, as I've argued that, in these cases, the

\footnotetext{
${ }^{34}$ Or at least none by virtue of their involvement, which is not to deny that a proposition like 'This river is $2 \mathrm{~m}$ deep today' is perspectival.
}

${ }^{35}$ We mustn't overstate how much that in itself shows, as all 'simple addition' requires is that a representation lack an element of perspective that prevents its endorsement alongside other truths. This is a weaker requirement than, for example, that its truth be predictable by broader laws. One might articulate this difference as one between a consequence of the requirement that the world be single and a consequence of the requirement that the world be simple - unified by some suitably small number of basic laws. For Moore, a representation's being 'absolute' depends on its meeting the 'simple addition' requirement; but for our key 'supposition', '[p]iecemeal endorsement will not be good enough' and '[i]ntegration is called for', 'or at least', he continues, 'indirect integration' (1997: 280, 22). That qualification points to the same murky waters that I discussed briefly in Sec. 4. 
supposed 'self-understanding' we miss is an illusion, a 'feat' to which we have given no sense. ${ }^{36}$

Finally, let us note an interesting and perhaps unexpected possibility that our discussion opens up concerning the form that grasp of an 'absolute conception' might

${ }^{36}$ The practices I have discussed would seem to instantiate what Moore calls 'nonexclusive outlooks', from which he distinguishes 'points of view' (1997: 81). (Cf. also his discussion (1997: 11-12) of how 'the radically perspectival' may be seen as 'absolute'.) The account I have presented makes a point analogous to that which Moore makes against varieties of transcendental idealism - namely, that we must not misconstrue the 'limits' of our different 'understandings of being' as 'limitations'. (Cf., e.g., Moore 2003 and forthcoming: 912.) That Heidegger might embrace this thought is a possibility that I suspect Moore would be inclined to reject, and that reflects a deeper disagreement between Moore and myself over 'the kind of bite that [Heidegger's claims] are meant to have' (forthcoming: 983). The above thought entails that a certain explanatory project must collapse - as 'the contingency of our conceptual sense-making ... disappear[s]' and '"[o]ur language" comes to admit of no alternative' (p. 537). That project, which I suspect Moore reads into Heidegger, is not unlike that which Moore sees in Wittgenstein and that which Lafont sees in Heidegger, namely, that of providing a kind of 'grounding of necessity in contingency' (Moore forthcoming: 529). So, for example, for Lafont, Heidegger's 'understandings of Being' are meant to be 'a priori arbitrary and indifferent' - and hence philosophically un-mysterious - but also 'a posteriori necessary and indispensable' (2000: 3) - which provides an explanation (of sorts) of how we come to find in our thoughts what we take to be necessities. Moore's Wittgenstein avoids idealist confusions in exploring that kind of 'grounding' solely because he rejects certain kinds of explanatory questions it might be taken to answer. (For example, '[w]e must not ask, "What does being an aunt consist in?"' (Moore forthcoming: 539)) But I see Heidegger's own work as, in some important respects, much closer to that of a Wittgensteinian 'reminding', than the kind of explanatory project Moore envisages. (For an indication of how this case might be made, cf. McManus 2008: sec. 4, forthcoming-a sec. 9.2, and forthcoming-c.) 
take. Williams talks at one point of 'local non-absolute conceptions of the world' ( $p$. 301); my sense is that to the extent that it makes sense to talk of the practices under discussion as 'local' - or indeed 'historical' or 'factical' - it need not follow that they are 'non-absolute', merely 'perspectival'. Williams talks of the need, if 'the absolute conception' were to be articulated, for 'concepts not peculiarly ours' (Williams 1978: 244); our discussion suggests that we struggle to see the practices we have been discussing as 'peculiarly ours' in the sense of embodying our view of the matters in question with which the view of some notional others might contrast. But if the representations that these practices yield are fit for inclusion in an 'absolute conception' of the world, then that suggests that grasp of such a 'conception' may not be best thought of as a 'disembodied' achievement: rather than the 'view from nowhere' being merely a view, it may instead be a feat calling for the mastery of certain specific practices, though not ones that are 'peculiarly ours' ${ }^{37}$

\section{Lafont's criticisms reconsidered}

Lets us return now to the three claims that Sec. 1 identified as the critical upshot of Lafont's reading. How precisely does the account I have offered respond to these claims? Let's begin with her worry that Heidegger's 'detranscendentalising' postulation of a plurality of 'disclosures' entails that 'the universal validity ascribed to truth is an illusion' (Lafont 2000: 61 n. 56). In the cases I have considered, we have found that we lack the conceptual room, so to speak, to think of what the practices in question reveal as embodying merely 'local' 'views' of what they reveal. To grasp the facts that these practices make available to us we must master those practices; but that does not entail that they reveal anything less than how the world really is in itself with respect to - for example - length: what these practices reveal is authoritative - is

\footnotetext{
${ }^{37}$ The question this possibility raises about a sharp distinction between 'manipulation' and 'seeing' - between 'the practical' and 'the cognitive' - is precisely one which Heidegger himself raises: 'it is by no means patent where the ontological boundary between "theoretical" and "atheoretical" behaviour runs!' (1962: 409)
} 
universally valid - for anyone who asks about lengths. One just might be tempted to claim that seeing how the world really is in itself would require that we see it without the above 'qualification', 'with respect to length', and that truth with genuinely universal validity is authoritative for absolutely anyone and not just anyone who asks about particular issues (here, lengths) - not just 'for those who share this projection' (Lafont 2000: 257). But from the perspective I have offered, and with my examples in mind, this requirement comes to look like the demand that one be able to derive answers from the world without posing it determinate questions. ${ }^{38}$

My response to Lafont's worry that any account of 'understandings of Being' as 'contingent absolutes' must be incoherent will take us back to the question raised in the previous section about how to understand Heidegger's 'detranscendentalization'. To begin, let us consider one of the no-doubt many objections that my account raises. ${ }^{39}$ The objection is this: isn't there something a little naïve about my account in our post-positivist era? If a 'disclosure' of the sort that I discuss is 'immunized against anything that could possibly contradict or question it' (Lafont 2000: 112), wouldn't such a 'disclosure' yield a set of 'basic propositions' of the sort in which no one believes anymore?

38 This, I suggest, is the sense in which '[i]n no case is a Dasein ... set before the open country of a "world-in-itself" so that it just beholds what it encounters', and the sense in which "there are in principle no "bare facts"” (Heidegger 1962: 213 and 414). Another possible source of the suspicion that Heidegger sees all truths as perspectival are claims such as that " "[t]here is" truth only in so far as Dasein is and so long as Dasein is ' (1962: 269) and I discuss this and related remarks at length in McManus forthcoming-a: sec. 7.5. The discussion above also has an obvious bearing on the interpretive question of why we ought to think of the 'understanding' that 'grounds' propositional truth as itself a (deeper, primordial) form of truth and I have discussed this question in McManus forthcoming-a: sec. 7.2 and forthcoming-b: sec. 6. ${ }^{39}$ I cannot hope to offer a full defence of my account here but I have attempted elsewhere to respond to some objections that the view from which this account is derived invites. Cf. McManus 2007 and forthcoming-a: sec.6.3 and ch. 7. 
My response is 'Yes and no': yes, in that we cannot imagine alternative perspectives on - or 'rival views' of - what they reveal but, no, in that we can imagine abandoning these practices, their 'output' no longer being of use to us. Wittgenstein talks, for example, of circumstances in which such practices would 'lose their point':

The procedure of putting a lump of cheese on a balance and fixing the price by the turn of the scale would lose its point if it frequently happened for such lumps to suddenly grow or shrink for no obvious reason. (Wittgenstein 1967: sec. 142)

Would we say that, under such circumstances, the findings arrived at through this procedure would be false? It seems more natural to say that it would be unclear what to say, that there would no longer seem to be something like a fact of the matter where once we had talked of 'the weight' of such lumps and held beliefs about such a property and such facts. Such beliefs might now come to seem to us useless, but not it seems to me - false or mistaken; this 'disclosure' might be discarded, but not 'contradicted'.

Hence, it would be misleading to apply to these 'disclosures' the description Lafont (2000: 3) takes from Hamann: 'a priori arbitrary and indifferent, but a posteriori necessary and indispensable'. I have suggested that there is no way of coming to confront the properties and facts that these practices reveal other than through those practices; but those practices are also 'not the (eternal) endowment of a transcendental ego' (Lafont 2000: xiv, quoted above) and there might be circumstances in which they would prove themselves eminently dispensable. These understandings are 'a fate into which humans are thrown' (2000: xiv) in that we can't imagine revising them; but we can certainly imagine not using them and it is this fact that entitles us to see these 'disclosures' as 'detranscendentalized', 'factical' or 'historical'.

Is the account of the waxing and waning of 'understandings of Being' set out above how Heidegger himself imagines this process? Possibly not. But then, for all the talk of 'the historical' in the early work, he says surprisingly little that might allow 
particular substantive interpretations of that talk to be defended. Later works talk of the 'granting' of a succession of 'epochs' in the 'understanding of Being'; but I, like Lafont (2000: 113, 252), find no clear story there about the 'mechanism', so to speak, by which one such 'epoch' succeeds another; nor is there any clear reason to think that those ideas play a role in Heidegger's early thought. Nevertheless, if 'projections of Being' are indeed 'subject to historical change', then something like the story I 
have sketched here would seem to be necessary if it is also the case that 'we cannot ask at all about the "correctness" of a projection'. ${ }^{40}$

Finally, let us look at Lafont's third worry. Given my understanding of 'understandings of Being' the worry that we cannot make sense of how one might replace another vanishes: different 'disclosures' do not rival one another in the sense

40 That story also raises a broader and - I think - very interesting philosophical question. A suspicion of mine is that a fixation on direct reference may conjure up illusory 'logical spaces' by reference to which one might imagine a 'disclosure' failing, beliefs it makes possible revealed as systematically false. Direct reference seems to be able to 'harpoon' - and allow us to hang on to - the world even while our beliefs undergo tumultuous fluctuations; it would seem to allow us to label even the most misguided of these beliefs as 'errors', as failing to miss their target but crucially - possessing that target nonetheless. Direct reference theorists might reject my suspicion, citing cases where directly referring expressions fail to pick out any particular individual (person, location, event, etc.) at all as ones in which the truth and falsity of claims made using those expressions are undermined. But the kinds of example I have discussed point us to the - Heideggerian and Wittgensteinian - thought that certain broad circumstances may be necessary if we are entitled to use the honorific, 'error'. The broader philosophical question, on which I can only touch here, is: under quite what circumstances - in which broader contexts of cognitive peace and quiet, as it were - can direct reference perform its distinctive feat? Which kinds of mastery of the world around us (including true beliefs) must we possess - how much 'stage-setting' must be place - for us to hang on to the line that direct reference attaches to the world and which 'enables us to transcend the limits of our beliefs' (Lafont 1999: xv and 2000: 8)? For example, while one might think that 'there is no reason whatever - intuitive or otherwise - to believe that having a word $\mathrm{S}$ that means $\mathrm{X}$ but not $\mathrm{Y}$ depends on being able, in principle, to tell Xs apart from Ys' (Boghossian 1990: 77), one might also think that 'our practice of using natural kind terms can exist and have the features that it does only because we have ... generally reliable abilities to re-identify particular specimens [of those kinds]' (Heal 1998: 104). 
that one might capture the same subject-matter better than another. But my account does invite a related worry, in that it might seem to make it difficult to understand how the practices I have described could have emerged in the first place through what one might call an 'intelligent' or 'intellectual' response on our part to the world. But there are at least two things to be said here.

Firstly, my account only rules out a hypothesis which - when brought out into the open - seems fanciful anyway; very crudely put, what we seem to mourn the passing of here is a story according to which we arrived at the practice of measuring lengths by judging - seeing directly, as it were - that objects were of certain lengths and then figuring out a handy way of ensuring these judgments were right, one involving the use of rulers. ${ }^{41}$ Secondly, and relatedly, I believe it may indeed be rather difficult to tell an 'intellectualist' story - one of a 'learning process' - about how such practices emerged. When a child learns them it is very much a matter of training; it seems much more natural to talk of their 'catching on to' or 'getting the hang of' such a practice, rather than, for example, their coming to see that it is, in some sense, 'right'. There would seem to be a similar distortion in imagining mankind first acquiring these practices 'by satisfying [it]self of [their] correctness' (Wittgenstein 1974: sec. 94).

Indeed the fact that it is the emergence of practices of the sort I have described that needs to be understood when we seek to 'understand the emergence of understandings of Being' gives us some reason to think the latter a tractable challenge and not one calling for a 'demiurgic language'. On my account, an example of grasping how 'understandings of Being' emerge would be grasping how people moved from comparing the length of particular objects to singling out a particular object as a general standard for measuring other objects, how the use of equivalent measuring objects became 'standard' in the sense of being used across a group rather than just by an individual, etc., etc. No doubt each of these innovations embodies 'a very large conceptual step' (Morley and Renfrew 2010: 3); but we can imagine these steps being made out of more primitive forms of behaviour. If nothing else, it seems to be an interesting possibility that the study of 'the emergence of understandings of

${ }^{41}$ Heidegger attacks an analogous view at 1962: 409-10. 
Being' might fall not, say, to the historian of science, but instead to the anthropologist or archaeologist. ${ }^{42}$

Plenty of questions remain, of course. For instance, are the examples of 'disclosures of being' that I have offered really the kinds of examples that Heidegger has in mind? Proving that they are would require the kind of textual case that I have not provided here. ${ }^{43}$ Such a case faces the difficulty that if there is one thing we lack in Heidegger's discussions of 'understandings of Being' in his work of the 1920s, it is examples: Haugeland acknowledges this explicitly $(2000: 71,72)$ and Lafont implicitly when she turns to discussion in lectures from 1935/36 (Heidegger 1967) in search of examples to fit her critical account. ${ }^{44}$ I do believe that the examples I have offered are in the spirit of Heidegger's earlier thinking and, for instance, follow on naturally from his repeated invocations of the idea of measurement and of measurement tools in his discussions of the 'founding' of propositional truth, invocations which I have argued Lafont misunderstands. My examples also, of course, have the virtue that they, and the vision of an 'understanding of Being' they

\footnotetext{
42 This may also offer a different way of addressing the well-known worry that Heidegger faces a difficulty in understanding how human intentionality relates to forms of animal awareness. Cf, e.g., Glendinning 1996, and Lafont's insistence that Heidegger saw a significant gulf here (cf. her 2000: 235-36) 'in spite of [his] efforts to establish finer distinctions' (2000: 246 n. 6).

${ }^{43}$ I attempt to provide a textual case for thinking that the account I draw on here does indeed capture Heidegger's view in my forthcoming-a.

${ }^{44}$ Cf. Lafont 1999: 260 n. 32 and 2000: 259-75.
} 
suggest, make possible a more charitable reading of these central themes in Heidegger's work. ${ }^{45}$

Denis McManus

Philosophy

Faculty of Humanities

University of Southampton

Southampton

SO18 1BJ

UK

mcmanus@soton.ac.uk

\section{$\underline{\text { References }}$}

Beck, A. (2005) 'Heidegger and Relativity Theory: Crisis, Authenticity and Repetition', Angelaki 10: 163-79.

Blattner, W. D. (1999), Heidegger's Temporal Idealism, Cambridge: Cambridge University Press.

${ }^{45}$ For helpful comments on material on which this article is based, and for other kinds of help besides, I would like to thank Maria Alvarez, Adam Beck, Taylor Carman, John Collins, John Divers, Sophia Efstathiou,_Sebastian Gardner, Paul Gilbert, Simon Glendinning, Cressida Heyes, Dylan Jaggard, Nicholas Joll, Oskari Kuusela, Joanna McManus, Penelope Mackie, Wayne Martin, Alex Miller, Ed Minar, Stephen Mulhall, Alex Neill, David Owen, Dawn Phillips, John Preston, Aaron Ridley, Tom Sheehan, Graham Stevens, Dan Watts, Daniel Whiting, Fiona Woollard and a referee for the journal. In addition, my work has benefited from the comments of members of audiences at research seminars at the Universities of East Anglia, Essex and Southampton, and at the conference, 'Art. Truth and Imagination', held in memory of Barrie Falk at the University of Birmingham. I would also like to thank the University of Southampton and the Arts and Humanities Research Council for periods of research leave during which work on which this article is based was done. 
Boghossian, P. (1990), 'Naturalizing Content', in G.Rey and B.Loewer (ed.) Meaning in Mind: Essays for Jerry Fodor, Oxford: Blackwell.

Carman, T. (2003), Heidegger's Analytic, Cambridge: Cambridge University Press.

-- (2002), 'Was Heidegger a Linguistic Idealist?', Inquiry 45: 205-16.

Chang, H. and Cartwright, N. (2008), 'Measurement', in S. Psillos and M. Curd (eds.) The Routledge Companion to Philosophy of Science, London: Routledge, pp. $367-75$.

Collins, H. and Evans, R. (2007), Rethinking Expertise, Chicago: University of Chicago Press.

Crowell, S. and Malpas J. (eds.) (2007), Transcendental Heidegger; Stanford, California: Stanford University Press.

Davidson, D. (1973-74), 'On the Very Idea of a Conceptual Scheme', Proceedings and Addresses of the American Philosophical Association 67: 5-20, reprinted in his Inquiries into Truth and Interpretation, Oxford: Oxford University Press, 1984.

Dreyfus, H. L. (2000), 'Responses', in Wrathall and Malpas 2000.

-- (2002), 'Comments on Christina Lafont's Intepretation of Being and Time', Inquiry 45: 191-4.

-- (2005), 'Foreword' to White 2005.

Dupré, J. (1983), 'The Disunity of Science', Mind 92: 321-46.

Farkas, K. (2008), The Subject's Point of View, Oxford: Oxford University Press.

Fodor, J. (1974), 'Special Sciences (or: The Disunity of Science as a Working Hypothesis)', Synthese 28: 77-115.

Glendinning, S. (1996), 'Heidegger and the Question of Animality', International Journal of Philosophical Studies 4: $67-86$.

Goldfarb, W. (1997), 'Metaphysics and Nonsense: On Cora Diamond's The Realistic Spirit', Journal of Philosophical Research 22: 57-73.

Haugeland, J. (1998), Having Thought, Cambridge, Mass.: Harvard University Press. -- (2000), 'Truth and Finitude: Heidegger's Transcendental Existentialism', in Wrathall and Malpas (2000). 
-- (2002), 'Authentic Intentionality', in M. Scheutz (ed.), Computationalism: New

Directions, Cambridge, Mass.: MIT Press.

-- (2007), 'Letting be', in Crowell and Malpas (2007).

-- (unpublished), ‘Two Dogmas of Rationalism', unpublished paper.

Heal, J. (1998), 'Externalism and Memory', Proceedings of the Aristotelian Society,

Supplementary Volume 72: 95-109.

Heidegger, M. (1962), Being and Time. Trans. J. Macquarrie and E. Robinson,

Oxford: Blackwell.

-- (1967), What is a Thing?, trans. W. B. Barton and V. Deutsch, Lanham: University

Press of America.

-- (1999), Contributions to Philosophy, trans. P. Emad and K. Maly, Indianapolis:

Indiana University Press.

Lafont, C. (1999), The Linguistic Turn in Hermeneutic Philosophy, trans.J. Medina,

Cambridge, Mass.: The MIT Press.

-- (2000), Heidegger, Language, and World-Disclosure, trans. G. Harman,

Cambridge: Cambridge University Press.

-- (2002), 'Replies', Inquiry 45: 229-48.

-- (2005), 'Was Heidegger an Externalist?', Inquiry 48:507 - 532.

Lear, J. (1984), 'The Disappearing “We”'. Proceedings of the Aristotelian Society,

Supplementary Volume 58: 219-258

McManus D. (1999), 'The Rediscovery of Heidegger's Worldly Subject by Analytic Philosophy of Science', The Monist 78: 324-346.

-- (2003), 'Wittgenstein, Fetishism, and Nonsense in Practice', in C. J. Heyes (ed.)

The Grammar of Politics: Wittgenstein and Political Philosophy, Ithaca:

Cornell University Press, pp. 63-81.

-- (2007), 'Heidegger, Measurement and the "Intelligibility" of Science', European

Journal of Philosophy 15: 82-105.

-- (2008), 'Rules, Regression and the 'Background': Dreyfus, Heidegger and

McDowell', European Journal of Philosophy 16: 432-58.

-- (forthcoming-a), Heidegger and the Measure of Truth, Oxford: Oxford University

Press. 
-- (forthcoming-b), 'Heidegger on Scepticism, Truth and Falsehood', in M. Wrathall (ed.) The Cambridge Companion to Being and Time, Cambridge: Cambridge University Press.

Moore, A. W. (1987), 'Points of View', The Philosophical Quarterly 37: 1-20.

-- (1997), Points of View, Oxford: Oxford University Press.

Moore, A. W. (2003) 'Ineffability and Nonsense', Proceedings of the Aristotelian Society, Supplementary Volume 77: 169-193.

-- (forthcoming), The Evolution of Modern Metaphysics: Making Sense of Things, Cambridge: Cambridge University Press.

Morley, I. and Renfrew, C. (eds.) (2010), The Archaeology of Measurement, Cambridge: Cambridge University Press.

Morris, M. (2007) An Introduction to the Philosophy of Language, Cambridge: Cambridge University Press.

Nagel, T. (1989), The View from Nowhere, Oxford: Oxford University Press.

Okrent, M. (2002), ‘Equipment, World and Language', Inquiry 45: 195-204.

Olafson, F. (1987), Heidegger and the Philosophy of Mind, New Haven: Yale University Press.

Rentsch, T. (1989), Das Sein und der Tod, Munich: Piper.

Rorty, R. (1972), 'The World Well Lost', Journal of Philosophy 64: 649-665.

Smith, W. H. (2007), 'Why Tugendhat's Critique of Heidegger's Concept of Truth remains a Critical Problem', Inquiry 50: 156-79.

Wikforss, A. (2001), 'Social Externalism and Conceptual Errors', Philosophical Quarterly 51: 217-31.

White, C. J. (2005), Time and Death: Heidegger's Analysis of Finitude, London: Ashgate.

Williams, B. (1974), 'Wittgenstein and Idealism', in G. Vesey (ed.) Understanding Wittgenstein, Royal Institute of Philosophy Lecture, vol. 7, London: Macmillan.

-- (1978), Descartes: The Project of Pure Enquiry, Harmondsworth: Penguin Books. Wittgenstein, L. (1967), Philosophical Investigations. Ed. G.E.M.Anscombe and R.Rhees, trans. G.E.M.Anscombe, Oxford: Blackwell. 
-- (1974), On Certainty, ed. G.E.M.Anscombe and G.H.von Wright, trans. D.Paul and G.E.M.Anscombe, Oxford: Blackwell.

Wrathall, M. A. (2002), 'Heidegger, Truth, and Reference', Inquiry 45: 217-28.

Wrathall, M. A. and Malpas, J. (eds.) (2000), Heidegger, Authenticity and Modernity. Cambridge, Mass.: The MIT Press.

Young, J. (1997) Heidegger, Philosophy, Nazism, Cambridge: Cambridge University Press. 